\title{
IMPERATIVOS DA BELEZA: CORPO FEMININO, CULTURA FITNESS E A NOVA EUGENIA
}

\author{
ANdré Luiz dos S. SiLVA*
}

\begin{abstract}
RESUMO: Este texto se propóe a discutir os atuais imperativos da beleza feminina, evidenciando marcas de uma nova eugenia em meio à cultura fitness. Para tanto, utilizo textos de Renato Kehl, destacado eugenista brasileiro que, em meio a seus escritos, propóe a exercitação física como promotora de saúde e embelezamento. A história da eugenia nos indica que esta ciência, capaz de legitimar regimes políticos totalitários e atrocidades contra a humanidade, construiu, também, um totalitarismo corporal, na medida em que elegeu a beleza como representação, desumanizando os corpos feios. As mulheres representadas pela cultura fitness contemporânea materializam, igualmente, a magreza e a simetria, construindo, assim como a eugenia, um corpo uníssono.
\end{abstract}

Palavras-chave: Eugenia. Cultura fitness. Beleza feminina.

\section{IMPERATIVE OF BEAUTY: FEMALE BODY, FITNESS CULTURE AND THE NEW EUGENICS}

ABSTRACT: This text proposes a discussion on the current female beauty imperatives, showing marks of a new eugenics in the midst of fitness culture. In order to do so, I use Renato Kehl's texts, remarkable Brazilian eugenics scholar, who in the midst of his writings proposes the physical exercise as health and beautification promoter. The history of eugenics shows us that science, able to legitimize totalitarian political regimes and atrocities against humanity, also built a body totalitarianism, in which beauty was elected as representation,

Doutorando em Ciências do Movimento Humano pela Universidade Federal do Rio Grande do Sul (UFRGS) e professor do curso de graduação em Educação Física e Pedagogia no Centro Universitário Feevale. E-mail: andrezaoufv@yahoo.com.br 
dehumanizing the ugly bodies. In the same way, the women represented by the contemporary fitness culture materialize the leanness and symmetry, building, as eugenics, a unison body.

Key words: Eugenics. Fitness culture. Female beauty.

$\sqrt{\pi}$ ste é um texto político e as linhas que seguem revelam um engajamento gestado em delicados temas sobre os quais tenho me debruçado. Encharcado pelas proposições dos estudos de gênero e da história cultural, meu olhar tem procurado os rastros deixados pela relação entre educação física e eugenia. ${ }^{1}$ Acessar os vestígios deixados pela ciência da melhoria da raça e conspirar com teorizaçōes marcadamente políticas, talvez, tenham me feito suspeitar de elementos que, nos dias de hoje, apresentam semelhanças com a eugenia, e é sobre isso que me proponho a discutir, por meio do presente texto.

Doping, introjeções tecnológicas, produções cinematográficas, mapeamento do DNA, obras literárias, pesquisas com células-tronco, mensagens publicitárias, seleção de óvulos e espermatozoides... As possibilidades de se pensar a nova eugenia são muitas. ${ }^{2}$ Entretanto, escolho refletir, neste texto, sobre a cultura fitness $^{3}$ e suas prescriçóes para os corpos femininos.

Entendo que um olhar um pouco mais atento para os corpos femininos produzidos pela cultura fitness nos revela semelhanças sensíveis ao que há tempos chamou-se eugenia. Prestar mais atenção à ciência $d a$ melhoria da raça, seus dizeres e anseios nos ajuda a pensar os atuais imperativos da beleza feminina.

Assim, meu percurso argumentativo transita entre o passado e o presente, a fim de problematizar as representações de corpo eleitas pelo universo da cultura fitness. Neste sentido, visito textos produzidos por Renato Ferraz Kehl (1889-1974), ${ }_{4}^{4}$ um dos mais significativos e influentes eugenistas brasileiros. Autor de dezenas de livros, artigos em revistas e eventos acadêmicos, Kehl coloca-se, nas páginas de seus textos, bastante preocupado com os corpos femininos, de onde foi possível retirar muitos elementos para pensar.

Dessa forma, tento evidenciar, aqui, os olhares eugênicos de Kehl sobre os corpos femininos, visibilizando as marcas de uma nova eugenia em meio à cultura fitness contemporânea. 


\section{Nos dizeres de Renato Kehl, a beleza como obrigação}

Datada de meados do século XIX, a eugenia constituiu-se como uma ciência nova que despertava facínio, sendo concebida pela intelectualidade da época como sinônimo de modernidade e avanço. Com o objetivo de melhoria da espécie, pela via da reprodução, seus mecanismos eram baseados na ordenação e classificação dos indivíduos, visando a incentivar a procriação de seres com características superiores, restringindo a proliferação de degenerados. Mesmo assumindo tons diferentes e dialogando com a peculiaridade do contexto brasileiro, a eugenia, nos primeiros anos do século XX, foi identificada como mais um saber legítimo que auxiliaria a civilizar, limpar e aperfeiçoar aquela heterogênea população (Silva, 2008).

Em meio a esse contexto, Kehl, médico e farmacêutico, proferiu a primeira conferência sobre o assunto em São Paulo, no ano de 1917. Desta data em diante, passou a se posicionar efetivamente na divulgação e na constituição da eugenia no Brasil, o que o levou, como dito, a publicar vários textos que tratam de temas como eugenia, saneamento e educação higiênica. Em meio às suas obras, a educação física é incorporada a um projeto de regeneração nacional para fortalecer o corpo do cidadão e o corpo de possibilidades de intervenção e propagação eugênica (idem, ibid.).

Em meio aos textos onde Kehl divulga e reafirma a necessidade das práticas de exercitação física, as mulheres recebem um lugar de especial cuidado. $\mathrm{O}$ modo como esse eugenista escreve sobre o sexo feminino constrói uma representação de corpo que dá forma aos imperativos da beleza, apontando as imperfeições corporais e presentificando a fealdade. Para ele,

Pouca gente sabe o que seja uma "bella mulher" (...). Raras, raríssimas as mulheres que podem ter a pretensão de serem rainhas da plástica, possuindo, a rigor, as justas proporçôes das partes, harmonia de linhas, esbeltez do talhe, delicadeza de contornos, epiderme rosada e fina, além dos predicados indispensáveis de saúde e robustez. (Kehl, 1927, p. 15-16)

Fragmentos como este aparecem em diversos momentos, indicando a beleza como algo que as mulheres não possuem, mas devem alcançar; são evidências que ganham mais vulto quando postas ao lado de tabelas e quadros que revelam o ideal simétrico dos corpos femininos. 
Imperativos da beleza: corpo feminino, cultura fitness e a nova eugenia

Construídas a partir de proporções matemáticas, as medidas destes recursos gráficos não se encontram nas formas de uma mulher de ossos e músculos. Essa normalidade considerada beleza, ao longo das obras de Kehl, torna-se um mito, um atributo quase incorpóreo (Goellner, 2003).

Kehl afirmava que as mulheres, por sua "natureza", eram mais propícias ao sedentarismo, ${ }^{5}$ optando por ficar em casa a desfrutar de um "salutar passeio a pé". Assim, vivendo entre quatro paredes, ao abrigo da luz e do ar puro, as mulheres definhavam, pouco a pouco, na sua inatividade (Silva \& Goellner, 2008).

Muito mais sujeitas ao acúmulo de gordura do que os homens, as mulheres - em especial, as casadas, as que se aproximam da velhice e aquelas que já deram à luz o primeiro filho - compunham, para Kehl, o triste quadro da deformidade ventral. Mulheres sedentárias são apontadas como possuidoras de "seios pendentes", "carnes moles", "excesso de gordura", "ventre abaulado", "braços gordos e roliços", "quadris exuberantes de tecido adiposo", entre outros termos pejorativos (idem, ibid.).

Como forma de evitar, amenizar ou até mesmo solucionar tais problemas, as ginásticas eram indicadas às mulheres. A imagem da mulher gorda, traduzida em exemplo de como não se deve ser, povoa os seus textos, cuja narrativa, reiteradamente, promove a graça, a beleza e a feminilidade daquelas que se movimentam.

Como exemplo salutar, Kehl constrói textos e imagens para evidenciar o corpo daquelas que se esforçam, dentro dos preceitos higiênicos e eugênicos, para constituírem seus corpos belos. Desse modo, a distante perfeição física é prometida a todas as mulheres disciplinadas na prática diuturna da ginástica, afinal tais exercícios torneariam as pernas, consumiriam o excesso de gordura, emagreceriam as "ancas" e o pescoço, cultivariam a robustez, a agilidade e a flexibilidade dos quadris, desenvolvendo, assim, o equilíbrio: "Como estheta, proclamo a necessidade da gymnastica entre as meninas e as jovens, único recurso para alcançar o ideal da belleza, pelo equilíbrio das partes e harmonia de todo o corpo (...)" (Kehl, 1927, p. 19).

Evidenciadas como detentoras de um poder que atrai e fascina, os corpos de mulheres que se exercitam são construídos por Kehl como exemplos de beleza e feminilidade, portanto sensuais e saudáveis. Esse corpo deve ser contemplado e imortalizado enquanto for jovem, magro, robusto e gracioso. A mulher bela, nas páginas em que o autor aborda a 
educação física, carrega a simetria das formas, a musculatura trabalhada, a gordura sem excesso, a pele lisa e branca, atributos que despertam o desejo.

Kehl pinta o ideal de corpo feminino dotado de uma beleza incomum, melhorada, eugenizada. Materializando os ideais eugenistas, por meio da legitimidade científica, Kehl constrói modelos de aperfeiçoamento feminino, reiterando a necessidade de práticas de beleza, entre elas a educação física.

Nos tempos da cultura fitness, o imperativo da beleza

Originário da língua inglesa, o termo fit tem o sentido de caber, ajustar, encaixar. Num primeiro olhar, o significado de fit in (adaptar-se) sugere conformismo e acomodação, mas se pensarmos nos termos da cultura fitness, remete a esforçar-se, aplicar-se, dedicar-se e, sobretudo, inconformar-se com os atributos de imperfeição, assimetria e defeito.

As noções de fit e unfit há tempos têm sido utilizadas para classificar e ordenar corpos, indicando os adequados e os inadequados. Vejamos uma passagem de Galton (1892, p. 18):

Os resultados estrondosos de uma herança maldita já haviam forçado estes conceitos [hereditariedade] na mente popular de forma que a indignação (perante as pessoas consideradas "impróprias") era expressa livremente, sem nenhum traço de desaprovação por parte de terceiros, a ponto de os inadequados [unfit] pais de filhos fracos e incapazes (...), serem considerados um sério estorvo para a nação. ${ }^{6}$ (Grifo do autor; tradução livre)

Francis Galton, intelectual que sistematizou a ciência da eugenia, em meados do século XIX, utilizava os termos fit e unfit para designar os sujeitos eugênicos e os degenerados. Adaptar, adequar, encaixar, caber e ajustar são verbos que nos possibilitam pensar o aperfeiçoamento corporal por meio da eugenia e da cultura fitness.

Aproximadamente cem anos depois do surgimento da ciência da melhoria da espécie, o radical fit se vê novamente presente em meio à ânsia por tornar os corpos aptos. Desde a década de 1980, a cultura fitness vem ganhando espaço. Roupas inteligentes, calçados que transformam o impacto em propulsão, desodorantes que eliminam o suor 
Imperativos da beleza: corpo feminino, cultura fitness e a nova eugenia

excessivo e garantem "proteção", mesmo ao corpo que se exercita exaustivamente... A cultura fitness está na arquitetura das academias de ginásticas, nos corpos dos personal trainers, na imponência dos aparelhos de musculação. A cultura fitness está em shopping centers, outdoors, capas de revistas, supermercados, programas de tevê, praças e parques. Extrapolando os lugares reservados à prática de exercícios físicos, atravessa as mais diversas instâncias do nosso cotidiano (Goellner, 2006). A cultura fitness, segundo Ortega (2008, p. 40),

(...) nos é apresentada como o "remédio universal", que nos garante: a independência da medicina (a qual se revela como sendo aparente); a proteção de todos os males da sociedade moderna - adiçóes de todo tipo (drogas, sexo, consumo), depressões e distúrbios alimentares -; a receita da felicidade (...).

Essa cultura faz parte do que Ortega (op. cit.) denomina cultura somática, um fenômeno descrito como um tipo específico de ascese contemporânea. A bioascese constitui-se pela ânsia dos cuidados corporais, um aumento de controle e atenção sobre o corpo. Procedimentos médicos e higiênicos, cuidados com alimentação, biotecnologia, fitness, entre outros, são alguns dos mecanismos cuja lógica necessita ser subjetivada e tornada ação. O resultado seria a criação de sujeitos capazes de autocontrole, de sentirem-se culpados por descuidos na alimentação, na atividade física, na ingestão de medicamentos, entre outros hábitos.

Tal qual a eugenia, a cultura fitness revela um fascínio sobre belos corpos e, ao elegê-los como símbolos da saúde - expressão máxima do autocontrole, da disciplina e do empenho -, posiciona a margem aqueles outros não tão belos, não tão magros e não tão jovens. Para além do radical fit, a cultura fitness guarda semelhança com a eugenia ao ordenar e classificar os corpos, ao eleger determinadas formas e execrar tantas outras.

Fitness indica ação, disposição, disciplina e pró-atividade, elementos que, nos dias de hoje, representam corpos magros, jovens, bem torneados, saudáveis e belos. Reconhecer esses adjetivos como hierarquicamente superiores, ou como foco de desejo que move corpos, significa identificar como negativos a indolência, o descuido e a invigilância.

Comedimento, disciplina e esforço individual são materializados em belos corpos, uma aparência autorizada a usar roupas justas e a proclamar os benefícios da vitória sobre a indolência. $\mathrm{Na}$ contramão destes 
corpos, a obesidade é representada como transgressora, um emblema do descontrole. O sobrepeso materializa nos corpos as "regras que governam o comer, o prazer e o controle de si", constantemente violadas (Fischler, 2005).

Nas nossas sociedades, a comida ocupa o lugar da sexualidade como fonte potencial de ansiedade e patologia. $\mathrm{O}$ tabu que se colocava sobre a sexualidade desloca-se agora para o açúcar, as gorduras e as taxas de colesterol. Os tabus passaram da cama para a mesa. O glutão sente-se, com frequência, mais culpado que o adúltero. (Ortega, op. cit., p. 40-41)

Cabe ressaltar, entretanto, que as carnes firmes e magras, corpos ágeis e disciplinados não são positivados somente nessa cultura contemporânea. Há quase um século, mulheres não tão magras são apontadas como relapsas e preguiçosas. Se nos dias de hoje, em meio à cultura fitness, impera uma supervalorização da magreza e do que ela representa, nos dizeres da eugenia de Kehl, é possível, igualmente, identificar o que Fischler (op. cit.) chama de "lipofobia". A mulher eugênica proposta por Kehl, assim como a mulher fitness dos dias de hoje, é ávida por seus deveres e, portanto, deve estar atenta a seu corpo, tentando extirpar quaisquer marcas de preguiça, indolência e indisciplina.

Uma vez que os elementos valorativos são atribuídos à pele lisa, aos músculos rijos, à vivacidade, ao belo contorno das formas, não são marginalizadas somente as mulheres "gordas". Rugas e cabelos brancos são indícios de envelhecimento, marcas corporais que devem ser diuturnamente postergadas.

Ler a eugenia brasileira do início do século XX e investigar o corpo feminino gestado nos seus dizeres tem feito pensar que esses critérios avaliativos não são tão novos como propõe Ortega (op. cit.). "Força, rigidez, juventude, longevidade, saúde e beleza" são critérios que, há mais de um século, têm sido reiterados e reinventados como fundamentais ao corpo feminino. Mulheres velhas não são evidenciadas por Kehl. As rugas e a flacidez muscular, típicas do processo de envelhecimento, são descritas por este eugenista como algo que deve ser permanentemente evitado.

Atualmente, a descoberta dessa parcela significativa da população pelo mercado talvez tenha dado visibilidades diferentes à velhice. Produtos, bens e serviços são oferecidos a essa população e, com isso, tem se 
Imperativos da beleza: corpo feminino, cultura fitness e a nova eugenia

construído uma representação do idoso jovem, disposto, vivaz, produtivo, ativo física e sexualmente. Representa-se um idoso limpo, belo, saudável, jovem - eugenizado.

Nos dias de hoje, a aceitação social passa pelos processos de prevenção e rejuvenescimento; nos tempos de Kehl, a velhice deveria ser retardada. Tanto hoje quanto há cem anos, as práticas de exercitação física são prescritas como elemento capaz de dotar os corpos de agilidade, vivacidade e beleza - adjetivos característicos da juventude.

Velhice, obesidade e feiura devem ser, no mínimo, atenuadas, enquanto a beleza se torna representação máxima de positividade, um imperativo para as mulheres - em meio à cultura fitness, a única possibilidade. Nas diversas manifestações dessa cultura, corpos dissonantes, quando aparecem, são para dimensionar corpos belos e conferir-lhes centralidade.

Essa mesma estratégia já era utilizada por Kehl, ao pintar corpos de mulheres não belas como abjetas, repugnantes, marcadas pela fealdade. A beleza, como materialização da saúde moral, intelectual e física, tornou-se emblema maior da ciência da eugenia, cujos esforços eram direcionados para sua conquista. Construída em meio às ciências biológicas e tornada ação pela medicina social, a feiura - signo de disgenia e degenerescência - deveria ser curada. Aos olhos de Kehl (1923, p. 27), "a fealdade é uma ferida que deve ser tratada como doença".

Asco, nojo, repugnância e náusea são sensaçôes associadas pela eugenia de Kehl à feiura humana, uma ferida aberta, suja, infecta, purulenta. Corpos tortos, malformados, de pele escura, cegos, mancos, defeituosos... Corpos rotulados pela eugenia, corpos doentes que deveriam ser curados.

Amigos que somos do bello, não podemos cruzar os braços ante a desfiguração plástica e psychica da humanidade, composta, nos nossos dias, de espectros de gente, genuínas figuras movediças, representados nos quadros da anormalidade. (Kehl, op. cit., p. 16)

A fealdade se evita, a fealdade se cura, já dizia Kehl em 1923. Dentro de seu projeto eugênico, ele propóe ainda a disciplina, o comedimento, o esforço individual e os conhecimentos acerca da hereditariedade e da eugenia. Muitas destas proposições ainda hoje são apontadas como capazes de dotar corpos desgraciosos de beleza e elegância, atribuindo às feias a responsabilidade por sua condição. $\mathrm{Na}$ cultura 
fitness, diferentemente da eugenia de Kehl, a feiura é ocultada. Membros malformados não são mostrados, corpos rotos são invisibilizados, talvez porque não devam existir naquele espaço. Para todas aquelas desgraciosas, cabe-lhes tornarem-se belas.

\section{Imperativos da beleza: indícios de uma nova eugenia}

São exteriorizações de sentimentos eugênicos os traços do pintor que representam na tela deusas da formosura. São eugênicos os contornos que o cinzel esculptor entalha no mármore, reproduzindo o ideal plástico da forma. (Kehl, 1920, p. 12)

Kehl exterioriza seus sentimentos eugênicos ao pintar e positivar a beleza. A cultura fitness manifesta, igualmente, uma sensibilidade eugênica ao representar as deusas da formosura em roupas de malha e exercitando-se fisicamente. Mesmo separadas por quase um século, a eugenia de Kehl e a cultura fitness aproximam-se ao evidenciarem corpos belos como única possibilidade.

A história da eugenia indica que esta ciência, voltada para o corpo biológico, foi capaz de legitimar regimes políticos totalitários e atrocidades contra a figura humana. A eugenia construiu, ainda, um totalitarismo corporal, na medida em que elegeu o corpo belo como única representação humana saudável e desejável. A beleza eugênica configurase, para mim, uma beleza totalitária, discriminatória e preconceituosa e, com isso, desumaniza todos os outros corpos.

Alta, magra, bronzeada, sarada, jovem, ativa, a cultura fitness representa uma mulher singular, uma mulher bela. A beleza torna-se, no seio dessa cultura, um imperativo, e os corpos que ali transitam respiram magreza, juventude, simetria. Considero que, assim como a eugenia, a cultura fitness constrói um corpo feminino uníssono, padronizado. Todas as outras formas femininas são estigmatizadas e excluídas.

Proeminências abdominais, pés grandes, culotes, varizes, cifose, estrabismo, calvície, pelos no corpo, manchas na pele, lordose, obesidade, velhice... corpos diferentes, membros distintos, tamanhos diversos - estes corpos não aparecem e talvez não devam aparecer. A eles, o dever de desempenar as costas, endireitar os olhos, limpar as imperfeições, tornarem-se eugênicos. 
Imperativos da beleza: corpo feminino, cultura fitness e a nova eugenia

O totalitarismo se faz corpo na história da eugenia. A atual cultura fitness, ao apontar a beleza como única possibilidade, indica-nos, da mesma forma, uma cultura totalitária e, por que não dizer, apontanos uma nova eugenia.

\section{Notas}

1. Também chamada de ciência da melhoria da raça, a eugenia legitimou cientificamente práticas de segregação, esterilização e extermínio de indivíduos ditos degenerados, em alguns países, ao longo da primeira metade do século XX.

2. A esse respeito, aponto: Silva e Moreno (2005); Silva e Goellner (2007), Goellner e Silva (2012).

3. Goellner (2006, 2008, entre outros) vem discutindo o conceito de cultura fitness em instâncias como o esporte, as práticas de embelezamento, a mídia, etc.

4. Neste texto, predominantemente, utilizo suas obras datadas de 1917 a 1929 , período mais fértil em discussōes acerca dos exercícios ginásticos.

5. Atualmente, há um profícuo debate acerca do sedentarismo, uma discussão que possui sentidos próprios do nosso tempo. A esse respeito, indico Fraga (2006).

6. "The striking results of an evil inheritance have already forced themselves so far on the popular mind, that indignation is freely expressed, without any marks of disapproval from others, at the yearly output by unfit parents of weakly children (...), and who are a serious encumbrance to the nation" (grifo meu).

\section{Referências}

FISCHLER, C. Obeso benigno, obeso maligno. In: SANT'ANNA, D.B. (Org.). Políticas do corpo: elementos para uma história das práticas corporais. São Paulo: Estação Liberdade, 2005.

FRAGA, A.B. Exercício da informação: governo dos corpos no mercado da vida ativa. Campinas: Autores Associados, 2006.

GALTON, F. Hereditary Genius: an inquiry into its laws and consequences. Londres: MacMillan, 1892.

GOELLNER, S.V. Bela, maternal e feminina: imagens da mulher na revista Educação Physica. Ijuí: Unijuí, 2003.

GOELLNER, S.V. Entre o sexo, a beleza e a saúde: o esporte e a cultura fitness. Labrys: Estudos Feministas, Brasília, DF, n. 10, p. 12, jun./ 
dez. 2006. Disponível em: <http://vsites.unb.br/ih/his/gefem/labrys10/ riogrande/silvana.htm>.

GOELLNER, S.V. A cultura fitness e a estética do comedimento: as mulheres, seus corpos e aparências. In: STEVENS, C.M.T.; SWAIN, T.N. (Org.). A construção dos corpos. Perspectivas feministas. Florianópolis: Editora Mulheres, 2008. p. 245-260.

GOELLNER, S.V.; SILVA, A.L.S. Biotecnologia e neo eugenia: olhares a partir do esporte e da cultura fitness. In: COUTO, E.S.; GOELLNER, S.V. O triunfo do corpo: polêmicas contemporâneas. Petrópolis: Vozes, 2012. p. $187-210$.

KEHL, R. Eugenia e Medicina Social: problemas da vida. Rio de Janeiro: Livraria Francisco Alves, 1920.

KEHL, R. A cura da fealdade: eugenia e medicina social. São Paulo: Monteiro Lobato \& Co-Editores, 1923.

KEHL, R. Bíblia da saúde (bygiene). Rio de Janeiro: Francisco Alves, 1926.

KEHL, R. Formulário da belleza: fórmulas escolhidas. Rio de Janeiro: Francisco Alves, 1927.

ORTEGA, F. O corpo incerto: corporeidade, tecnologias médicas e cultura contemporânea. Rio de Janeiro: Garamond, 2008.

SILVA, A.L. A perfeição expressa na carne: a educação física no projeto eugênico de Renato Kehl (1917 a 1929). 2008. Dissertação (mestrado em Ciências do Movimento Humano) - Escola de Educação Física da Universidade Federal do Rio Grande do Sul, Porto Alegre.

SILVA, A.L.; GOELLNER, S.V. Sedentárias e coquettes à margem: corpos e feminilidades desviantes na obra de Renato Kehl. Pensar a Prática, Goiânia, v. 11, n. 3, p. 50-63, set./dez. 2008.

SILVA, A.L.; GOELLNER, S.V. Universo biotecnológico e fronteiras partidas: esporte, gênero e novo eugenismo. Revista Gênero, Niterói, v. 7, n. 2, p. 79-89, 2007.

SILVA, A.L.; MORENO, A. Frankenstein e cyborg: pistas no caminho 
Imperativos da beleza: corpo feminino, cultura fitness e a nova eugenia

da ciência indicam o "novo eugenismo". Pensar a Prática, Goiânia, v. 8, n. 2, p. 125-139, 2005.

Recebido em 5 de abril de 2011.

Aprovado em 30 de junho de 2012. 